\title{
Contribuição dos cursos de especialização lato sensu para o desenvolvimento do campo da Comunicação
}

Maria Cristina Castilho Costa Professora livre-docente do Departamento de Comunicações e Artes da Escola de Comunicações e Artes da Universidade de São Paulo.

Editora da Revista Comunicação \& Educação

E-mail: criscast@usp.br

Embora esta seção esteja destinada preferencialmente para o relato dos projetos de intervenção desenvolvidos pelos gestores de Comunicação formados pelo curso de Gestão da Comunicação da ECA-USP, neste número, excepcionalmente, vou relatar o que foi abordado em importante Mesa Temática - $A$ Contribuição dos Cursos de Especialização Lato Sensu para o Desenvolvimento do Campo da Comunicação - no XXIX Congresso Brasileiro de Ciências da Comunicação - Intercom, realizado de 4 a 9 de setembro de 2006 na UnB - Universidade de Brasília.

A idéia de falar a respeito dos cursos de especialização surgiu no primeiro semestre deste ano no Fórum Nacional em Defesa da Qualidade do Ensino em Comunicação - ENDECOM - que ocorreu em maio de 2006, na Escola de Comunicações e Artes da USP. Nesse evento, a prof ${ }^{\underline{a}}$ dr $^{\mathrm{a}}$ Margarida Kunsch propôs uma mesa-redonda sobre os cursos chamados de lato sensu, em nível de pós-graduação, que formam especialistas em determinada área do conhecimento.

O sucesso nas discussões havidas nesse evento estimulou-nos a sugerir o mesmo debate na Intercom, com o objetivo de mostrar que esses cursos cumprem importante função no desenvolvimento da ciência, no atendimento à sociedade e na profissionalização dos alunos. Diante de uma platéia atenta e questionadora, falamos por duas horas a respeito da sociedade, dos profissionais da comunicação e da necessidade de agilidade para responder a questões emergentes dessa área do conhecimento. O que passarei a desenvolver fez parte do conteúdo de minha palestra. 
comunicação \& educação • Ano XII • Número 1 • jan/abr 2007

\section{FORMAÇÃO HUMANISTA x ESPECIALIZAÇÃO}

Quando, no início da década de 1990, o Departamento de Comunicações e Artes da ECA-USP resolveu criar um curso novo de Comunicação em nível de pós-graduação lato sensu, deu início a uma pesquisa junto a diversos profissionais da área da Comunicação, com o intuito de saber quais eram as necessidades emergentes do mercado e qual o perfil profissional que empresas privadas, estado e organizações em geral estavam requisitando. Muitos profissionais e intelectuais ouvidos foram unânimes em afirmar que o perfil desejado pelo mercado e com futuro promissor na área de Comunicação era aquele com formação humanista, de caráter multidisciplinar e cultura universalista, capaz de entender a situação sobre a qual atua e toda a conjuntura que a envolve e cerca.

O profissional de que as organizações necessitam deve ter uma formação oposta àquela pretendida pela grande maioria dos cursos de graduação das Escolas de Comunicações que, após um ou, no máximo, dois anos de formação geral, direciona o aluno para a especialização, seja em uma das mídias tradicionais como rádio e televisão, seja em áreas de atuação de fronteiras reconhecíveis como publicidade ou relações públicas.

Os argumentos a favor da formação universalista e não-especializada eram muitos. A maioria dos cursos voltados à especialização tende a uma visão instrumentalista e técnica da profissão, formando profissionais muito semelhantes uns aos outros, capazes de manejar recursos técnicos e administrativos, mas com pouca capacidade de diagnóstico, de percepção das diferenças e de soluções não convencionais. Os entrevistados eram unânimes em afirmar que os desafios do mundo atual não podem ser vistos através de um manual de ações pré-planejadas, porém exigem uma análise profunda e questionadora.

Roberto Civita, presidente da Editora Abril, em recente visita à Escola de Comunicações e Artes, reafirmou essa visão do profissional da comunicação. Disse ele aos professores que a universidade não deveria formar técnicos, pois nisto as empresas eram bastante competentes - a própria Abril mantém um curso de Jornalismo no qual seleciona seus repórteres e redatores. Caberia, segundo ele, à Academia, formar profissionais com vasta bagagem teórica, cultural e humanista, pois isso a prática profissional em suas ações cotidianas não é capaz de promover.

Diante dessas informações, o Departamento de Comunicações e Artes, ao criar o curso de Gestão da Comunicação, optou justamente por privilegiar a formação teórica com ênfase nas humanidades - história, ciências sociais, filosofia, estética, educação. O coração desse programa era, naturalmente, as Ciências da Comunicação.

\section{MULTIDISCIPLINARIDADE x DEPARTAMENTALIZAÇÃO}

Indo ao encontro dessa primeira idéia mestra acerca da formação profissional do comunicador solicitado pela sociedade, pesquisas desenvolvidas na ECA, como as que a prof ${ }^{-1} \mathrm{dr}^{\mathrm{a}}-$ Maria Immacolata Vassalo de Lopes realiza há anos com 
os egressos dos cursos de Comunicação, mostram que os alunos raramente são alocados nas áreas profissionais nas quais têm especialidade: jornalistas ocupam cargos de assessoria de imprensa, cuja formação é de responsabilidade dos cursos de Relações Públicas, assim como radialistas e profissionais de TV dedicam-se ao jornalismo e à publicidade nesses veículos. Esse cenário revela que a especialização nem sequer promove uma reserva de mercado para o formando. E, num país de poucos veículos de comunicação e muito desemprego, não há como respeitar os limites departamentais que envolvem a especialização.

Recentemente, a Folha de S. Paulo publicou uma matéria a esse respeito, intitulada $53 \%$ dos formandos no país trabalham em outras áreas ${ }^{1}$. O jornalista Antônio Gois, apoiado em dados do IBGE, comenta a imensa dispersão dos universitários que acabam por trabalhar em empregos que nada têm a ver com

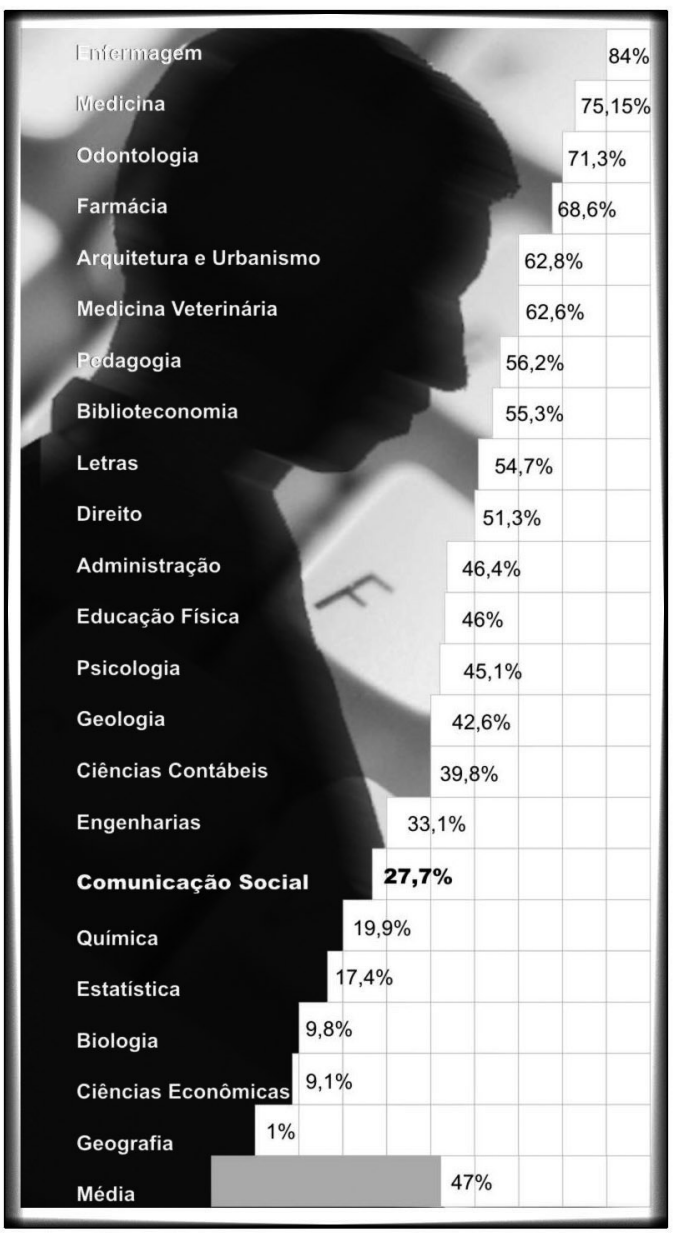

Correlação entre formação e emprego: na área de comunicações, apenas $27,7 \%$ atuam na carreira. suas carreiras. As razões são muitas, mas algumas pessoas entrevistadas pelo jornalista encontram deficiências no ensino médio e certa pressa das famílias e das escolas em fazer o jovem decidir precocemente a carreira a seguir. O que espanta nessa matéria é o quadro de correlação entre formação e emprego, no qual a área de comunicações é uma das que apresentam um baixo índice de correlação. Apenas 27,7\% dos profissionais estão trabalhando em atividades para as quais foram formados.

Assim, com aquelas premissas citadas, o Departamento de Comunicações e Artes preocupou-se com um curso que, centrado nas Ciências da Comunicação, procurasse fugir da especialização e da departamentalização acadêmica, direcionando o aluno para a realidade do mercado. Isso significava torná-lo apto a atuar em diferentes situações e frentes, capacitando-o a coordenar as ações de diferentes especialistas, atuando como articulador.

\section{TERCEIRIZAÇÃO E REENGENHARIA}

Na mesma direção das questões aqui expostas, outras pesquisas orientaram os criadores do curso de Gestão da Comunicação para essa abordagem univer-

1. GOIS, Antônio. $53 \%$ dos formandos no país trabaIham em outras áreas. Folha de S. Paulo, p. 1, 11 set. 2006. Cotidiano. 
sal e plural da Comunicação. Uma delas apontava para as conseqüências dos processos de reengenharia empresarial e da intensa multiplicação dos contratos de terceirização, especialmente nos departamentos de Comunicação. O fato de assessores de imprensa, jornalistas, publicitários e profissionais de marketing passarem a ser prestadores de serviço para as empresas para as quais trabalhavam, traz modificações significativas para o exercício profissional. Uma delas é a insegurança que esses contratos de curto prazo e sem qualquer garantia de renovação suscitam, obrigando os trabalhadores envolvidos a manterem seu próprio escritório e novos clientes, como uma alternativa de sobrevivência. Outra conseqüência, que atua sobre os profissionais que permanecem como funcionários na empresa, é que eles terão de agir não como especialistas, mas como coordenadores de diversas atividades de comunicação contratadas ou realizadas fora da organização. O desenvolvimento dessa competência para a coordenação ou gestão raramente faz parte dos currículos ordinários das Escolas de Comunicação.

Diante dessa nova realidade do mercado de trabalho do comunicador, a figura do gestor de comunicação começava a se delinear de forma mais clara - um profissional não-especialista, com formação predominantemente teórica e capaz de intermediar ações praticadas por diversos profissionais. Esse gestor seria capaz de, continuando a trabalhar na empresa, coordenar essas diferentes ações e processos, assim como, tendo seu próprio escritório, enfrentar a multiplicidade de situações que diferentes clientes trazem ou propõem.

Para acentuar as cores e contrastes desse cenário, as empresas tendem, atualmente, a concentrar o maior número de atividades no menor número possível de pessoas, sejam funcionários, prestadores de serviço ou fornecedores. Isso nos permite dizer que o futuro aspira cada vez menos por especialistas e cada vez mais por gestores, articuladores e coordenadores de atividades e pessoas.

\section{A COMUNICAÇÃO GENERALIZADA}

Mas as mudanças que somos capazes de observar na sociedade e que alteram o perfil do comunicador não atingem apenas esse profissional. Outros profissionais vêem seu trabalho exigir novas competências para as quais não foram formados, inclusive o manejo e domínio de linguagens tecnológicas que, antes, eram prerrogativas de quem se especializa em Comunicação. O advento das mídias digitais, o avanço do computador como ferramenta de trabalho, a internet e as intranets fizeram com que todo profissional necessite de mínima noção sobre linguagens tecnológicas e interações comunicativas. Isso causa uma procura, por parte de uma grande variedade de profissionais, de informações e conhecimentos que os tornem aptos a agir com segurança em seu trabalho. As pesquisas realizadas pelo Departamento de Comunicações e Artes mostraram que médicos, advogados, terapeutas ocupacionais, profissionais de instituições públicas, entre outros, sentem falta de conhecimentos básicos dos processos comunicacionais para o exercício de sua profissão. 
Contribuição dos cursos de especialização lato sensu • Maria Cristina Castilho Costa

Ficava evidente a necessidade de mecanismos de formação em nível de pós-graduação para capacitar tais profissionais, permitindo que, diante de uma tecnologia que propõe autonomia, pudessem dela fazer uso correto e consciente.

Por outro lado, as mesmas transformações estruturais que colocam aos mais diferentes profissionais esses desafios, fazem com que pequenos e médios empresários também busquem informações para poder fazer frente à racionalidade e à competitividade que predominam na sociedade como um todo. Fazer publicidade, relacionar-se com o público, possuir mala direta e informatizar seu estabelecimento não são mais termos só usados pelas corporações. Pequenos negócios passam a fazer parte de redes de comunicação e necessitam de um mínimo de entendimento de como assegurar seu sucesso.

Nesse cenário, a Comunicação, antes ferramenta sofisticada das grandes corporações, populariza-se e passa a ser uma preocupação geral de diferentes profissionais e de uma variada gama de organizações e segmentos de mercado.

\section{TERCEIRO SETOR x ESTADO}

A maioria dos cursos de graduação existentes foi criada em uma época em que os meios de comunicação eram geridos basicamente pelo Estado ou por grandes empresas concessionárias, o que mantinha próximas e íntimas as relações entre Comunicação e poder. Na desregulamentação da vida social que presenciamos na última década, assistimos a um Estado que decresce de importância e a um setor privado que se torna cada vez mais decisório. Como conseqüência, da própria sociedade tem emergido novas formas de organização e administração pública - atividades voltadas para a solução de problemas que, tradicionalmente tidos como de responsabilidade do Estado, hoje exigem novos esforços e novas soluções. $\mathrm{O}$ atendimento às crianças, às populações carentes, aos imigrantes e aos injustiçados e excluídos tem ficado sob responsabilidade de uma área nova da sociedade chamada genericamente de Terceiro Setor. Procurando distinguir-se do Primeiro Setor, representado pelo Estado, e do Segundo, em que atuam as empresas privadas, o Terceiro Setor congrega associações, fundações e organizações não-governamentais voltadas à proteção do meio ambiente, à defesa de minorias e à solução de problemas emergentes que atingem parcelas da população.

A mobilização da sociedade civil em defesa dessas causas tem obtido resultados compensadores, quer na solução dos problemas, quer no fortalecimento das relações comunitárias ou, até mesmo, na conscientização da sociedade como um todo para a existência de novas necessidades sociais. Tais movimentos, entretanto, formados muitos deles no calor da oportunidade - ou da necessidade -, encontram grandes dificuldades de sobrevivência, manutenção e crescimento, pois faltam recursos humanos, financeiros e administrativos. Um profissional tem vindo em auxílio da estruturação desses movimentos. É o comunicador, essencial para manter vivas as relações com a sociedade e para auxiliar no estabelecimento de procedimentos que garantam a sobrevida do grupo. 
comunicação \& educação • Ano XII • Número 1 • jan/abr 2007

As pesquisas demonstram que a Comunicação se torna cada vez mais importante em todas as ações do Terceiro Setor, bem como em todos os movimentos sociais que não contam com a benevolência do Estado nem com os recursos advindos da iniciativa privada. Terceiro Setor e movimentos sociais têm na mídia e na comunicação um de seus mais importantes focos.

\section{COMUNICAÇÃO \& EDUCAÇÃO}

É claro que esse universo mutante envolvendo empresas, organizações em geral e o mercado de trabalho teria de se refletir de forma contundente na educação. As pesquisas mostraram a necessidade urgente de que a Comunicação não fosse disciplina apenas dos programas universitários, mas que fizesse parte da educação fundamental e média. As razões são muitas e falaremos agora de algumas delas.

Hoje, com o desenvolvimento dos meios de comunicação, não é apenas a escola que educa os jovens, mas também a mídia. O tempo e a atenção que crianças e adolescentes devotam ao consumo midiático exigem que as linguagens audiovisuais sejam conhecidas e decifradas. A alfabetização midiática do jovem deve fazer parte de sua formação escolar, permitindo que ele perca o olhar ingênuo e distraído que tem diante dos meios de comunicação de massa e que o transformam em presa fácil das mensagens midiáticas. Um olhar mais interpretativo e sagaz vai melhor prepará-lo para interagir com a mídia. Como disse Orozco em recente entrevista à revista Comunicação \& Educação: é preciso que a escola incorpore o desenvolvimento de novos modelos epistemológicos originados nas novas tecnologias da comunicação².

Além disso, a educação do público, fazendo com que ele torne-se cada vez mais apto à decifração das mensagens midiáticas, parece ser o único recurso para melhorar a qualidade das informações e dos programas veiculados pela mídia. Não é a proibição, mas a educação, a leitura crítica e o debate que formarão um público mais exigente, cuja atenção será veementemente disputada pelas empresas de comunicação dispostas a satisfazê-lo em suas mais diversas necessidades.

Não bastassem esses argumentos, sabemos ainda que todas as atividades produtivas, com maior ou menor intensidade, exigem conhecimentos e tecnologias de comunicação. Logo, uma escola que, desconhecendo essa tendência, exclua de seu currículo a Comunicação, não estará preparando adequadamente seus alunos para a sociedade na qual vão atuar.

Por todas essas considerações, o Departamento de Comunicações e Artes viu-se na contingência de organizar um curso de Gestão que privilegiasse a

2. OROZCO GOMEZ, Guillermo. Comunicação de massa na era da internet. Comunicação \& Educação, São Paulo: CCA-ECAUSP/Paulinas, ano XI, n. 3 , set./dez. 2006. inter-relação entre Comunicação e educação. Pensando no ensino formal e na preparação de novos profissionais atualizados; nas televisões e rádios educativas e em suas peculiaridades; na possibilidade de formar um público consciente e crítico, deu-se conta da urgência de preparar um comunicador para a formação de pessoas e de um público cada vez mais amplo. 


\section{TECNOLOGIA E ÉTICA}

Nessa busca por descobrir as mais novas tendências no campo da Comunicação, levando-se em conta não só as empresas especializadas, mas a sociedade como um todo, o mercado de trabalho, a formação profissional e o público em geral, chegamos à questão tecnológica - o advento das mídias digitais provoca uma ampla revolução na sociedade, modificando as relações de trabalho, as formas de poder e os relacionamentos, além de demolir antigas fronteiras entre trabalho e entretenimento. Conhecer profundamente a importância das tecnologias de comunicação, buscando entender sua semântica e a maneira como se relacionam com o usuário e como estabelecem diálogo entre as pessoas, é imprescindível para a formação do comunicador na atualidade.

Esse domínio tecnológico, todavia, não pode estar orientado para uma valorização desmedida da tecnologia em detrimento das pessoas envolvidas. Saber estabelecer limites e diferenças entre o tecnológico e o humano, colocando o primeiro a serviço do segundo, é também um importante exercício para o gestor. Igualmente importante para esse profissional que emerge do desenvolvimento atual da sociedade são as preocupações éticas da Comunicação.

O gestor da Comunicação é um profissional que pensa sua atividade como criação de espaços de interlocução, e não como simples emissão de informações unidirecionais e centralizadas em uma única fonte. Consciente do papel da Comunicação na vida contemporânea, esse profissional deve atuar de forma ética e democrática, procurando, antes de tudo, preservar o direito à informação, a liberdade de expressão e o acesso ao conhecimento. Somente colocando o que sabe a serviço desses princípios, ele estará agindo de modo autônomo e independente e fazendo da Comunicação um espaço de relacionamento e diálogo.

\section{SURGE O GESTOR}

Com todas as considerações vindas de pesquisas realizadas no âmbito da universidade, assim como da leitura de autores de ponta - que tratam cada vez mais da interdisciplinaridade na criação do conhecimento, como Edgar Morin; da fragmentação dos discursos, como Gianni Vattimo; da importância da Comunicação na cultura contemporânea, como Nestor García Canclini; da necessidade de se introduzir a Comunicação como disciplina escolar, como Jésus Martín Barbero; da importância da Comunicação na sociedade globalizada, como Octavio Ianni -, a figura do gestor de Comunicação tomou corpo: um profissional com forte formação humanista e multidisciplinar, articulador, mediador, politicamente engajado e eticamente comprometido.

A formação complexa desse comunicador é a de um especialista que, tendo se graduado e experimentado o mercado de trabalho, esteja voltado para as questões mais profundas da área e da sociedade, necessitando um conhecimento mais denso e crítico. Nessa direção, os cursos lato sensu atuam de forma mais 
ágil e rápida, podendo responder às necessidades emergentes. Enquanto a pósgraduação stricto sensu exige um longo tempo para que os profissionais por ela formados possam responder às mudanças no cenário social, os cursos lato sensu servem como laboratório especial no qual é possível testar teorias e modelos.

As monografias dos alunos do curso de Gestão da Comunicação, do Departamento de Comunicações e Artes da ECA - que completou doze anos de existência -, comprovam a capacidade desse laboratório de gerar, de forma rápida e segura, conhecimento no campo da Comunicação. Os projetos de intervenção, muitos deles desenvolvidos na prática, trazem uma bibliografia atualizada e de ponta, pesquisa de campo sistematizada e soluções criativas e exeqüíveis para os problemas focados. Além de toda essa contribuição, ainda estimula os alunos a ingressarem na pós-graduação stricto sensu, engrossando a fileira dos que vêem na Comunicação não só um espaço de ação, mas também de reflexão científica.

Resumo: $O$ artigo traz o relato do que foi abordado na Mesa Temática - A contribuição dos Cursos de Especialização Lato Sensu para o Desenvolvimento do Campo da Comunicação -, no XXIX Congresso Brasileiro de Ciências da Comunicação - Intercom, realizado de 4 a 9 de setembro de 2006 na UnB - Universidade de Brasília. O debate teve o objetivo de mostrar que esses cursos cumprem importante função no desenvolvimento da ciência, no atendimento à sociedade e na profissionalização dos alunos. A autora relatou a experiência do Departamento de Comunicações e Artes ao criar o curso de Gestão da Comunicação, que optou por privilegiar a formação teórica com ênfase nas humanidades - história, ciências sociais, filosofia, estética, educação. Destaca o estímulo ao ingresso na pós-graduação stricto sensu, favorecendo a Comunicação não só como um espaço de ação, mas também de reflexão científica.

Palavras-chave: Ciências da Comunicação, especialização lato sensu, gestão da Comunicação, Intercom 2006.
Abstract: The article brings the discussions of the thematic session Contribution of Graduate Courses in Lato Sensu to the Field of Communication Development, in the XXIX Brazilian Congress of Communication Sciences - INTERCOM, held from the $4^{\text {th }}$ to the $9^{\text {th }}$ of September 2006, at UnB - University of Brasilia. The debate had the objective of showing that those courses have an important role in the science development, society attendance and students professionalization. The author reported the experience of the ECA's Communications and Arts Department with the creation of the course Communication Management, that privileges the theoretical formation with emphasis in Humanities - History, Social Sciences, Philosophy, Aesthetics and Education. She highlights the incentive to ingress the stricto sensu graduate program, favoring the Communication field as a space of action and of scientific reflection.

Keywords: Communication Sciences, graduate courses in lato sensu, Communication management, Intercom 2006. 